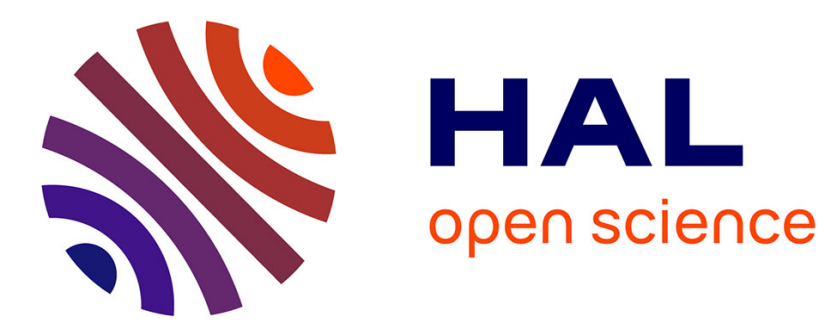

\title{
CO2 removal: Is a new simplified device could extended the indications?
}

Laurent Papazian, Samir Jaber

\section{To cite this version:}

Laurent Papazian, Samir Jaber. CO2 removal: Is a new simplified device could extended the indications?. Anaesthesia Critical Care \& Pain Medicine, 2015, 34 (3), pp.131 - 132. 10.1016/j.accpm.2015.03.001 . hal-01760110

\section{HAL Id: hal-01760110 \\ https://hal.umontpellier.fr/hal-01760110}

Submitted on 7 Nov 2018

HAL is a multi-disciplinary open access archive for the deposit and dissemination of scientific research documents, whether they are published or not. The documents may come from teaching and research institutions in France or abroad, or from public or private research centers.
L'archive ouverte pluridisciplinaire HAL, est destinée au dépôt et à la diffusion de documents scientifiques de niveau recherche, publiés ou non, émanant des établissements d'enseignement et de recherche français ou étrangers, des laboratoires publics ou privés. 


\section{$\mathrm{CO}_{2}$ removal: Is a new simplified device could extended the indications?}

In the present issue of the journal, Godet et al. [1] reported in an in vivo animal study including 15 pigs, the safety and feasibility use of a device based on a Prismaflex ${ }^{\mathbb{R}}$ platform in removing $\mathrm{CO}_{2}$ from the blood, thus decreasing $\mathrm{PaCO}_{2}$ and acidosis hypercapnia. The technique was based on a standard renal replacement therapy (RRT) platform (Prismaflex ${ }^{\mathbb{R}}$ ) that can be easily implemented on existing devices. This strategy used a novel stand alone gas exchanger kit incorporating a hollow fiber chamber without any RRT hemofilter. Although, the authors evaluated the effects on a short term period (less than 2 hours) and reported the efficiency by decreasing blood $\mathrm{CO}_{2}$, the effects on a long term period should be evaluated in both animal and human future studies especially in non-healthy lungs.

Invasive mechanical ventilation is lifesaving for patients with acute respiratory distress syndrome (ARDS). However, we know for about 30 years that positive pressure mechanical ventilation is able to create lung injuries and to worsen previous lung injuries (ventilator-induced lung injury; VILI). To minimize these VILI, it is generally recommended limiting tidal volume (VT) to $6 \mathrm{~mL} / \mathrm{kg}$ of predicted body weight and plateau pressure less than $30 \mathrm{cmH}_{2} \mathrm{O}$. However, evidence is accumulating that it may not be fully protective against VILI and the less positive pressure ventilation is given, the less VILI are created. The price to pay this limited VT is a reduction of minute ventilation even if respiratory rate is increased, leading a respiratory hypercapnia so called "permissive hypercapnia". The first extracorporeal $\mathrm{CO}_{2}$ removal $\left(\mathrm{ECCO}_{2} \mathrm{R}\right)$ devices were designed 40 years ago. The technique never entered into clinical practice, probably because high blood flows were necessary, extracorporeal circuits were not biocompatible, large catheters were used and full anticoagulation was required.

$\mathrm{ECCO}_{2} \mathrm{R}$ is capable of eliminating at least $50 \%$ of the calculated $\mathrm{CO}_{2}$ production, with rapid normalization of respiratory acidosis. This has led to the attempt of this technique in patients presenting with acute hypercapnic respiratory failure (COPD patients, bridge to transplant lung patients) [2]. $\mathrm{ECCO}_{2} \mathrm{R}$ systems are now proposed to reduce invasiveness of mechanical ventilation and, therefore, VILI in ARDS patients [3-7].

The older systems were driven by the arterio-venous pressure gradient; thus, cannulation of an arterial vessel (usually the femoral artery) was necessary for driving the system. Recent pump-driven veno-venous systems have been designed and are able to improve respiratory acidosis without requiring arterial cannulation. There are also some attempts to adapt continuous renal replacement devices to be able to clear $\mathrm{CO}_{2}$ by specially designed filters. Clinical experience suggests that high flow rates are needed to correct severe respiratory acidosis $(\mathrm{pH}<7.2)$. In this regard, the physiological relationships between cannula size, blood flow, sweep gas flow and gas transfer capacity, respectively, still remain largely unknown. For this reason, more physiological data on these issues are needed before the promising technique of miniaturized veno-venous $\mathrm{ECCO}_{2} \mathrm{R}$ can be tested in randomized controlled trials (RCTs) aiming to evaluate the possible beneficial clinical impact. Recently, a porcine study [7] indicated that pumpdriven veno-venous $\mathrm{ECCO}_{2} \mathrm{R}$ required a blood flow of 750 to $1000 \mathrm{~mL} / \mathrm{min}$ to normalize $\mathrm{pH}$ values and reduce $\mathrm{PaCO}_{2}$ in severe life-threatening respiratory acidosis under constant ventilatory support. Therefore, using low-diameter catheters and low blood flow rates, pump-driven veno-venous $\mathrm{ECCO}_{2} \mathrm{R}$ may be primarily feasible in patients with mild to moderate respiratory acidosis. This may be aimed at reducing aggressiveness of invasive ventilation in patients with ARDS. Recently Grasso et al. [6] showed that the use of $\mathrm{ECCO}_{2} \mathrm{R}$ permitted to reduce respiratory rate from 30 to 14 breaths/min while removing 39\% of $\mathrm{CO}_{2}$ production. Interestingly some cytokines (interleukin-6 and tumor necrosis factor- $\alpha$ ) concentrations were significantly lower in plasma and in bronchoalveolar lavage, suggesting that $\mathrm{ECCO}_{2} \mathrm{R}$ is also capable to limit biotrauma.

Since intensive care specialists are familiar with hemodialysis catheters, it is necessary to test whether these catheters also qualify for $\mathrm{ECCO}_{2} \mathrm{R}$. The maximal blood flow through these catheters is usually restricted to approximately $400 \mathrm{~mL} / \mathrm{min}$. Furthermore, catheters specifically designed for $\mathrm{ECCO}_{2} \mathrm{R}$ aim to avoid recirculation $\left(\mathrm{PCO}_{2}\right.$ of the venous blood, which is directed towards the oxygenator, is lower than arterial $\mathrm{PCO}_{2}$ ). Recirculation was obvious when hemodialysis catheters were used, even with low blood flow [7]. Recirculation has not been evaluated in the Godet et al. study [1].

Using a pumpless extracorporeal lung assist, Bein et al.'s [4] randomized 79 ARDS patients were enrolled to receive a low VT ventilation $\left(3 \mathrm{~mL} / \mathrm{kg}\right.$ ) combined with extracorporeal $\mathrm{CO}_{2}$ elimination, or to a ARDS-Net strategy (6 mL/kg) without the extracorporeal device. Ventilator-free days (VFD) within 60 days were not different between the two groups. However, in the more hypoxemic patients $\left(\mathrm{PaO}_{2} / \mathrm{FIO}_{2}<150 \mathrm{mmHg}\right)$ VFD-60 was higher in the $\mathrm{ECCO}_{2} \mathrm{R}$ group suggesting that next trials should focus on this moderate to severe ARDS group [4].

The concept of $\mathrm{ECCO}_{2} \mathrm{R}$ evolved in response to early trials of ECMO where the high incidence of adverse events and mechanical complications relegated the therapy to only the sickest of patients as a last ditch effort $[4,8,9]$. Furthermore, the high cost and complexity of the extracorporeal membrane oxygenation (ECMO) systems limited their use to a small number of high volume 
specialized medical facilities. As the technology and understanding of extracorporeal gas exchange has improved, further reductions in the incidence of adverse events and mechanical failures have been achieved by:

- advances in hollow fiber membrane technology, in terms of reductions in the fiber diameter and wall thickness, and prevention of plasma leakage to reduce the need for gas exchanger replacements;

- more sophisticated arrangements of hollow fiber membranes which reduce priming volume, reduce resistance to both blood and sweep gas flow through the device, and improve the gas exchange efficiency allowing for reduced fiber surface area and/ or circuit flow rate;

- the use of centrifugal pumps or non-occlusive pressure controlled roller pumps, which reduces damage to the blood (hemolysis) and the incidence of circuit rupture;

- biocompatible coatings on the fibers and circuit components (such as heparin), which reduce the risk of clot formation as well as the necessary levels of systemic anticoagulation;

- the use of single dual-lumen catheters and percutaneous venous cannulation, which reduces the incidence of cannulationassociated adverse events as well as the level of patient discomfort;

- simplifications in the system design to reduce risk of mechanical failure and operator error;

- use of active mixing of blood adjacent to the fibers to increase gas exchange efficiency, which allows for reduced fiber surface area and/or reduced blood flow;

- use of arterial-to-venous cannulation to eliminate the need for a pump.

Finally, the study of Godet et al. [1] showed that a simple technique based on a standard RRT platform (Prismaflex ${ }^{\mathbb{R}}$ ) could be easily implemented on existing devices. In the future, such a device could be used associated with the lung protective or ultralung protective ventilation in more ICU patients in extended indications.

\section{Disclosure of interest}

Conflict of interest of Samir JABER: Dr Jaber reports receiving consulting fees from Dräger, Hamilton, Maquet and Fisher Paykel

Conflict of interest of Laurent PAPAZIAN: Laurent PAPAZIAN do not have any conflicts of interest to declare regarding this manuscript.

\section{References}

[1] Godet T, Combes A, Zogheib E, Jabaudon M, Futier E, Slutsky AS, et al. Novel CO removal device driven by a renal-replacement system without hemofilter. A first step experimental validation. Anesth Crit Care Pain Med 2015. http:// dx.doi.org/10.1016/j.accpm.2014.08.006.

[2] Roze H, Repusseau B, Ouattara A. Extracorporeal membrane oxygenation in adults for severe acute respiratory failure. Ann Fr Anesth Reanim 2014;33:492-4.

[3] Abrams DC, Brenner K, Burkart KM, Agerstrand CL, Thomashow BM, Bacchetta $\mathrm{M}$, et al. Pilot study of extracorporeal carbon dioxide removal to facilitate extubation and ambulation in exacerbations of chronic obstructive pulmonary disease. Ann Am Thorac Soc 2013;10:307-14.

[4] Bein T, Weber-Carstens S, Goldmann A, Muller T, Staudinger T, Brederlau J, et al. Lower tidal volume strategy (approximately $3 \mathrm{~mL} / \mathrm{kg}$ ) combined with extracorporeal $\mathrm{CO}_{2}$ removal versus "conventional" protective ventilation $(6 \mathrm{~mL} / \mathrm{kg})$ in severe ARDS: the prospective randomized Xtravent-study. Intensive Care Med 2013;39:847-56.

[5] Burki NK, Mani RK, Herth FJ, Schmidt W, Teschler H, Bonin F, et al. A novel extracorporeal $\mathrm{CO}_{2}$ removal system: results of a pilot study of hypercapnic respiratory failure in patients with COPD. Chest 2013;143:678-86.

[6] Grasso S, Stripoli T, Mazzone P, Pezzuto M, Lacitignola L, Centonze P, et al. Low respiratory rate plus minimally invasive extracorporeal $\mathrm{CO}_{2}$ removal decreases systemic and pulmonary inflammatory mediators in experimental. Acute Respir Distress Syndrome. Crit Care Med 2014;42:e451-60.

[7] Karagiannidis C, Kampe KA, Sipmann FS, Larsson A, Hedenstierna G, Windisch $\mathrm{W}$, et al. Veno-venous extracorporeal $\mathrm{CO}_{2}$ removal for the treatment of severe respiratory acidosis: pathophysiological and technical considerations. Crit Care 2014;18:R124.

[8] Azoulay E, Citerio G, Bakker J, Bassetti M, Benoit D, Cecconi M, et al. Year in review in Intensive Care Medicine 2013: II. Sedation, invasive and noninvasive ventilation, airways, ARDS, ECMO, family satisfaction, end-of-life care, organ donation, informed consent, safety, hematological issues in critically ill patients. Intensive Care Med 2014;40:305-19.

[9] Roncon-Albuquerque Jr R, Carona G, Neves A, Miranda F, Castelo-Branco S, Oliveira $\mathrm{T}$, et al. Venovenous extracorporeal $\mathrm{CO}_{2}$ removal for early extubation in COPD exacerbations requiring invasive mechanical ventilation. Intensive Care Med 2014;40:1969-70.

Laurent Papazian ${ }^{\mathrm{a}, *, \mathrm{~b}}$

antensive care unit "acute respiratory failure and severe infections", Assistance publique-hôpitaux de Marseille, CHU Nord, 13015 Marseille, France

${ }^{\mathrm{b}}$ Faculté de médecine, Aix-Marseille university, URMITE UMR CNRS 7278, 13005 Marseille, France

Samir Jaber ${ }^{\mathrm{c}}$

'Intensive Care Unit and Transplantation, Critical Care and Anesthesia Department (DAR B), Saint-Eloi Hospital, University of Montpellier, INSERM U1046, CNRS UMR 9214, 34295 Montpellier cedex 5, France

${ }^{*}$ Corresponding author E-mail address: laurent.papazian@ap-hm.fr (L. Papazian) 